\title{
Broadband multimodal emission in Sb-doped CaZnOS-layered semiconductors
}

\author{
$\mathrm{Xu} \mathrm{\textrm {Li } ^ { 1 \dagger }}$, Yuantian Zheng ${ }^{1 \dagger}$, Ronghua $\mathrm{Ma}^{1 \dagger}$, Zefeng Huang ${ }^{1}$, Chunfeng Wang ${ }^{1}$, Mingju Zhu ${ }^{1}$, \\ Fuchun Jiang ${ }^{1}$, Yangyang $\mathrm{Du}^{2}$, Xian Chen ${ }^{2}$, Bolong Huang ${ }^{3}$, Feng Wang ${ }^{4}$, Bohan Wang ${ }^{5}$, Yu Wang ${ }^{5}$ and \\ Dengfeng Peng ${ }^{1 *}$
}

\begin{abstract}
Mechanoluminescent (ML) smart materials are expected to be used in stress sensors, new displays, and advanced flexible optoelectronic devices, because of their unique mechanical-to-light energy conversion properties. However, the narrow-range $\mathrm{ML}$ emission characteristics of single materials limit their application scope. In this work, we report on the broadband multimodal emission in Sb-doped CaZnOS layered semiconductors. A series of CaZnOS layer-structured powders with different $\mathrm{Sb}^{3+}$ doping concentrations were synthesised using a high-temperature solid-phase method. The $\mathrm{CaZnOS}: \mathrm{Sb}^{3+}$ phosphor achieved a wide range of ML spectra (400-900 nm), adjustable photoluminescence with double luminescent peaks located at 465 and $620 \mathrm{~nm}$, and the X-rayinduced luminescence characteristics were systematically studied. We have also achieved ultra-broad warm white light ML emission of $\mathrm{Sb}^{3+}$ and $\mathrm{Bi}^{3+}$ co-doped samples. Therefore, it can be expected that these ML phosphors will be used in smart lighting, displays, visible stress sensors, and $\mathrm{X}$-ray imaging and detections.
\end{abstract}

Keywords: doping, light emission, mechanoluminescence, CaZnOS, semiconductors

\section{INTRODUCTION}

Mechanoluminescence (ML) is a phenomenon in which an object directly emits light under mechanical stimulation. In contrast to common photoluminescence (PL) and electroluminescence $(\mathrm{EL})$, the process of $\mathrm{ML}$ does not require the object to be electrically charged or photonically illuminated, and thus it has unique potentials in the fields of new light sources, stress sensors, energy conversion and so on [1-6]. The phenomenon of $\mathrm{ML}$ is ubiquitous in nature, and it typically occurs when stones/minerals are broken, or when natural objects or artifacts are rubbed, abraded, impacted, or stretched by external forces. Because the earliest discovered ML phenomenon is essentially a fracture-destructive luminescence, unlike PL and
EL, few materials have gained practical applications in the long history of development. In 1999, Xu et al. [7] performed nondestructive testing of stress distribution using elastic ML materials. Since then, studies on ML have attracted intensive attention in the fields of inorganic and organic materials $[6,8]$. Among ML materials, inorganic materials have good chemical stability, repeatable mechanical-to-light energy conversion properties, and high brightness, and they have progressed rapidly with the development of advanced optoelectronic technologies [2]. To date, many new ML materials have been discovered, including $\mathrm{Li} / \mathrm{NaNbO}_{3}: \mathrm{Pr}^{3+}[9], \mathrm{Sr}_{3} \mathrm{Sn}_{2} \mathrm{O}_{7}: \mathrm{Nd}^{3+}[10]$, and CaZnOS: $\mathrm{Mn}^{2+} / \mathrm{Cu}^{2+} / \mathrm{Ln}^{3+}\left(\mathrm{Ln}=\mathrm{Sm}^{3+}, \mathrm{Er}^{3+}, \mathrm{Nd}^{3+}, \mathrm{Pr}^{3+}, \mathrm{Tb}^{3+}\right.$, $\mathrm{Eu}^{3+}, \mathrm{Dy}^{3+}, \mathrm{Ho}^{3+}, \mathrm{Tm}^{3+}$, and $\mathrm{Yb}^{3+}$ lanthanide ions) [11-21]. Most of the reported ML inorganics can emit light in a linear or narrow-band characteristic emission under doping; for example, the spectrum width of $\mathrm{Ln}$ ion emission is only several nanometres, and that of the transitional metals such as $\mathrm{Mn}$ is several tens of nanometres. The emission lines of a single dopant are not continuously distributed on the spectral axis. Therefore, several ML materials should be combined to obtain a wide range of ML spectra for specific applications, such as wind/droplet-driven displays [22,23]. However, ML materials doped with different ions have different pressure thresholds, which limit their operability [24]. Therefore, with the development of clean environmental energy and smart sensing promoted by ML technologies, suitable ion-doped ML materials with broad spectra, such as white light emission, are urgently needed [3,4,25-27].

In this work, we successfully synthesised a Sb-doped CaZnOS semiconductor using a high-temperature solid-phase method $[19,20]$. The prepared CaZnOS:Sb ${ }^{3+}$ not only exhibited excitation-dependent PL, but also had a broad spectrum of ML emissions. When different excitations are chosen, peak-dominated tunable PL can be realised from 465 to $620 \mathrm{~nm}$. Additionally, our samples can be sensitive to X-ray-excited visible light emissions. The achieved ML emission range is approximately $120 \mathrm{~nm}$ wider than that of commercially available $\mathrm{ZnS}$ : $\mathrm{Mn}^{2+}$. This discovery will play a unique role in the fields of no-

\footnotetext{
${ }^{1}$ Key Laboratory of Optoelectronic Devices and Systems of Ministry of Education and Guangdong Province, College of Physics and Optoelectronic Engineering, Shenzhen University, Shenzhen 518060, China

${ }^{2}$ College of Materials Science and Engineering, Shenzhen University, Shenzhen 518060, China

${ }^{3}$ Department of Applied Biology and Chemical Technology, The Hong Kong Polytechnic University, Hung Hom, Kowloon, Hong Kong SAR 999077, China

${ }^{4}$ Department of Materials Science and Engineering, City University of Hong Kong, Hong Kong, Hong Kong SAR 999077, China

${ }^{5}$ International Collaborative Laboratory of 2D Materials for Optoelectronics Science and Technology of Ministry of Education, SZU-NUS Collaborative Innovation Center for Optoelectronic Science \& Technology, Institute of Microscale Optoelectronics, Shenzhen University, Shenzhen 518060, China

$\dagger$ These authors contributed equally to this work.

* Corresponding author (email: pengdengfeng@szu.edu.cn)
} 
power displays, anti-counterfeiting, warm white lighting, stress/ pressure sensing, and mechanical energy-related fields.

\section{EXPERIMENTAL SECTION}

\section{Materials preparation}

We chose CaZnOS as the semiconductor in our study owing to its unique physical properties for realising high-performance ML. A series of $\mathrm{Ca}_{1-x} \mathrm{ZnOS}: x \mathrm{Sb}^{3+}(x=0 \%, 0.1 \%, 0.2 \%, 0.5 \%, 1 \%$, $1.5 \%, 2 \%, 3 \%, 4 \%, 6 \%$, and $8 \%$ ) samples were prepared by applying solid-state reactions according to our previous reports $[19,20]$. The starting raw materials were high-purity $\mathrm{ZnS}$ (Aladdin, 99.99\%), $\mathrm{CaCO}_{3}$ (Sigma-Aldrich, >99\%), high-purity $\mathrm{Sb}_{2} \mathrm{O}_{3}$ (Alfa Aesar, 99.999\%), $\mathrm{MnCl}_{2} \cdot 4 \mathrm{H}_{2} \mathrm{O}$ (Sinopharm Chemical Reagent Co., Ltd., 99.0\%), and $\mathrm{BiCl}_{3}$ powder (Alfa Aesar, $99.9 \%$ metal basis). A total of $20 \mathrm{~g}$ of raw materials was precisely weighed according to the stoichiometric ratio and then thoroughly mixed by wet grinding in $30 \mathrm{~mL}$ absolute ethanol. Then, we placed the raw materials in an oven set at $80^{\circ} \mathrm{C}$ for drying, after which they were placed in a corundum firing boat and heated to $1100^{\circ} \mathrm{C}$ at $10^{\circ} \mathrm{C} \mathrm{s}^{-1}$ under a $\mathrm{N}_{2}$ (purity, 99.99\%) protective atmosphere, and then calcined for $4 \mathrm{~h}$. After being cooled to room temperature naturally, the sintered sample was taken out and ground to fine powder for further characterisation.

\section{Characterizations}

The structure and morphology distribution of the samples were characterised by X-ray diffraction (XRD) and scanning electron microscopy (SEM). The equipment used for recording XRD was a Bruker D2 phase XRD analyser, whereas SEM was performed using a 3 Hitachi SU 8020 scanning electron microscope. Energy-dispersive X-ray (EDS) element maps were characterised using a HOBIRA EMAX X-ray detector. PL spectra were recorded using a Hitachi F-4600 spectrophotometer equipped with an R928 photomultiplier detector. The photos and videos were taken with a Sony ILCE-7M3 camera. The equipment used to obtain ML spectroscopy was a home-built measuring apparatus consisting of a linear motor, digital push-pull gauge, and QE65pro fibre optic spectrometer (Ocean Optics). X-rayinduced luminescence (XIL) spectra were studied using an Omni- $\lambda$ 300i spectrograph (Zolix) equipped with an X-ray tube (Model RACA-3, Zolix Instruments Co., Ltd., Beijing, China). In the ML test, we used a centrifuge tube to weigh out $0.3 \mathrm{~g}$ of the sample powder, $0.06 \mathrm{~g}$ of ultraviolet (UV)-curable glue, and added $9 \mathrm{~mL}$ of anhydrous alcohol. The constituents were shaken and mixed thoroughly and then dispersed in an ultrasonic bath. Finally, using the suspension-deposition method, the sample was evenly distributed in a $3 \mathrm{~cm} \times 3 \mathrm{~cm}$ area on an EVA-PET plastic encapsulation film (Deli, No. 3817). After the alcohol was completely volatilised, the sample was irradiated and cured with a UV lamp (LEAFTOP 9307) to obtain an ML test piece for the follow-up ML test.

\section{RESULTS AND DISCUSSION}

To evaluate the effects of our dopant on the structure of the samples, we first studied them using powder XRD, as shown in Fig. 1a. We found that the main phase was consistent with the standard library (PDF\#01-076-3819) for our sample CaZnOS: $x \%$ $\mathrm{Sb}^{3+}(x=0-8)$ fired by the high-temperature solid-phase method. It can be clearly seen from the XRD pattern that each doping concentration contains a mass amount of unreacted $\mathrm{ZnS}$ [12] (Fig. S1). The impurity phase disappeared when the doping concentration was $0.2 \%$, indicating that the reaction was sufficient in this case. From the XRD diffraction peak, $\mathrm{Sb}^{3+}$ ions enter the CaZnOS matrix below $2 \%$ doping concentration and do not markedly change the macro-crystalline structure of the CaZnOS host [28]. When the doping concentration of $\mathrm{Sb}^{3+}$ exceeded $2 \mathrm{~mol} \%$, the $\mathrm{Sb}_{2} \mathrm{O}_{3}$ phase peak appeared in the XRD pattern (Fig. S1). Fig. $1 \mathrm{~b}$ shows the SEM image of the $\mathrm{Sb}^{3+}$-doped CaZnOS $(0.2 \%)$. It can be seen that the prepared particles are

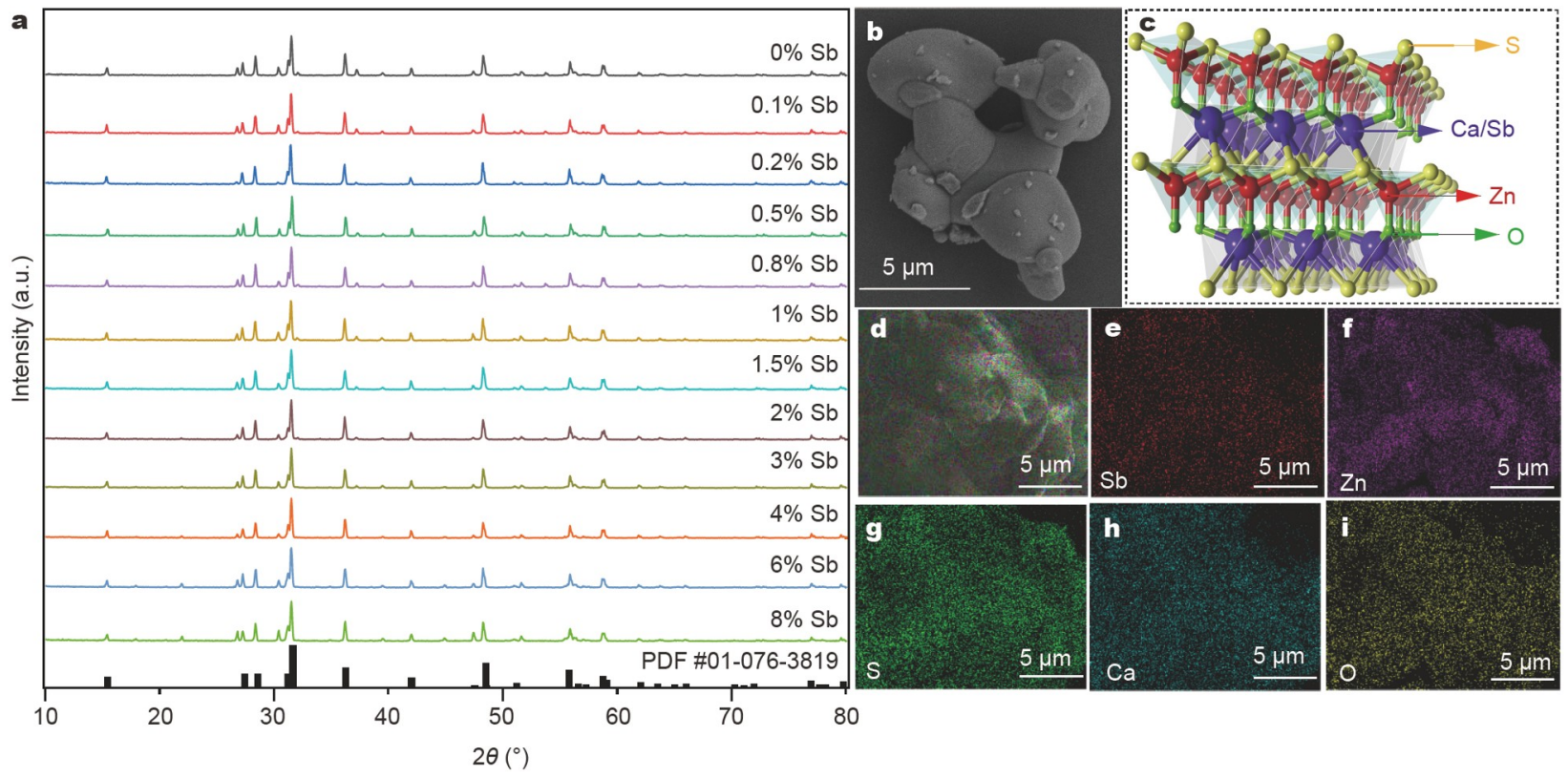

Figure 1 (a) XRD patterns of CaZnOS: $x \mathrm{Sb}^{3+}(x=0,0.1 \%, 0.2 \%, 0.5 \%, 0.8 \%, 1 \%, 1.5 \%, 2 \%, 3 \%, 4 \%$, 6\%, and $8 \%)$ samples. (b) SEM image of the representative CaZnOS particle $\left(1 \% \mathrm{Sb}^{3+}\right)$. (c) Schematic diagram of the crystal structure of $\mathrm{CaZnOS}$, representing the ions that make up the crystal: Ca/Sb (blue), Zn (red), O (green), and S (yellow). (d) EDS mapping of CaZnOS:Sb ${ }^{3+}$. (e-i) Elemental distribution diagrams of Sb (e), Zn (f), S (g), Ca (h), and O (i), confirming the uniform distribution of the elements in the sample. 
stacked by single-layer flakes of CaZnOS, and the overall appearance presents an irregular agglomerated shape, which is a typical morphology of particles prepared by high-temperature solid-phase methods [29]. Combined with the EDS analysis (Fig. 1d-i), Sb can be detected at every point in the detection area, which further indicates that $\mathrm{Sb}^{3+}$ ions are successfully and uniformly doped into the CaZnOS.

Fig. 2a shows the PL spectra of CaZnOS:1 mol\% $\mathrm{Sb}^{3+}$. Interestingly, we found that one PL spectrum contained two emission bands, one centred at $465 \mathrm{~nm}$ and the other at $620 \mathrm{~nm}$. Both emission bands are in the visible range of the human eye; the blue light emission located at $465 \mathrm{~nm}$ starts at $420 \mathrm{~nm}$ and stretches to $550 \mathrm{~nm}$, while the orange light emission band is $597-622 \mathrm{~nm}$. This phenomenon appeared in all the samples (Fig. S2). It is worth noting that two different emission bands are from one luminescent centre, which has also been observed in many organics and inorganics [28-31], but is rare in the previously reported CaZnOS matrix. Different light intensity ratios were observed for the 620 and $465 \mathrm{~nm}$ main emission peaks when the samples were excited with 280 and $340 \mathrm{~nm}$ UV light, indicating that the energy level transitions of $\mathrm{CaZnOS}_{\mathrm{Sb}^{3+}}$ corresponding to excitation light are different [32].

We recorded the excitation spectra monitored at 465 and $620 \mathrm{~nm}$. Two main absorption peaks were observed at 280 and $340 \mathrm{~nm}$. It is worth noting that there is a downward depression at $280 \mathrm{~nm}$ in the excitation spectrum when monitored at $465 \mathrm{~nm}$, which indicates that most of the charge transfer energy during excitation with $280-\mathrm{nm}$ excitation light is released by the red emission, and a small proportion is released by the blue emission. To further reveal the luminescence mechanism, we tested the luminescent decay of the sample (Fig. 2b), and the three attenuation processes of 280-620, 340-620, and 340-465 nm (excitation wavelength-emission wavelength), and their afterglow times were fitted for calculation (Fig. S3). Only one short-lived process was observed at $340-620 \mathrm{~nm}$, and there was a long-lived process and a short-lived process at 280-620 and $340-465 \mathrm{~nm}$, respectively. Therefore, it is reasonable to speculate that there is a fast transition process and a slower transition process in the $\mathrm{PL}$ of $\mathrm{Sb}^{3+}$ ions. In addition, the decay time of $280-620 \mathrm{~nm}$ is significantly longer than that of the other two excitation-emission wavelengths, which indicates that there is a longer electron transfer process in the process of red emission excited by 280 -nm light. Therefore, we next investi- gated the mechanism of $\mathrm{Sb}^{3+} \mathrm{PL}$ electron transition and energy transfer in $\mathrm{Sb}^{3+}$-doped CaZnOS.

The use of $n s^{2}$ electronically arranged elements ( $\mathrm{Sb}, \mathrm{Sn}$, and $\mathrm{Pb}$ ) as the luminescent centre of luminescent materials has been widely studied [33-35]. They usually have two sets of energy level distributions [36-38]. Their excited states are ${ }^{1} \mathrm{P}_{1}$ and ${ }^{3} \mathrm{P}_{x}$ $(x=2,1,0)$, while their corresponding ground states are ${ }^{1} \mathrm{~S}_{0}$. Typically, ${ }^{1} \mathrm{P}_{1}$ is called a singlet state and ${ }^{3} \mathrm{P}_{x}(x=2,1,0)$ is called a triplet state, such that $n \mathrm{~s}^{2}$ ions have a total of four independent excited states: ${ }^{1} \mathrm{P}_{1},{ }^{3} \mathrm{P}_{0},{ }^{3} \mathrm{P}_{1}$, and ${ }^{3} \mathrm{P}_{2}$. The energy level split of the ion is caused by the electron interaction and spin-orbit coupling principle in the ion, and the ${ }^{3} \mathrm{P}$ orbital energy level is split into $J=0,1,2$, which can be attributed to the Russell-Saunders coupling [34]. It is generally believed that the electron transfer of ${ }^{1} \mathrm{~S}_{0} \rightarrow{ }^{3} \mathrm{P}_{0}$ or ${ }^{1} \mathrm{~S}_{0} \rightarrow{ }^{3} \mathrm{P}_{2}$ is prohibited in the energy level transition of the ion. At the same time, owing to the spin-orbit coupling, the electron transfer between ${ }^{1} \mathrm{~S}_{0} \rightarrow{ }^{1} \mathrm{P}_{1}$ and ${ }^{1} \mathrm{~S}_{0} \rightarrow{ }^{3} \mathrm{P}_{1}$ is a parityallowable transition $[39,40] . \mathrm{Sb}^{3+}$ ions have a typical $5 \mathrm{~s}^{2}$ electronic state. Its common spectral absorption and emission originate from the corresponding electronic transition energy between the ground state ${ }^{1} \mathrm{~S}_{0}$ and singlet state ${ }^{1} \mathrm{P}_{1}$ (high energy level) and triplet state ${ }^{3} \mathrm{P}_{1}$ (low energy level), respectively. There is also an electron transfer channel from ${ }^{1} \mathrm{P}_{1}$ to ${ }^{3} \mathrm{P}_{1}$, called intersystem crossing (ISC) between the two energy levels [30]. We describe the electron transfer schematic diagram of $\mathrm{Sb}^{3+}$ ions in CaZnOS:Sb ${ }^{3+}$ in Fig. $2 \mathrm{c}$.

Combining our above descriptions of the PL and the decay curves, we can conclude that the $620-\mathrm{nm}$ emission is attributed to the ${ }^{3} \mathrm{P}_{1} \rightarrow{ }^{1} \mathrm{~S}_{0}$ transition. Under excitation by the $280-\mathrm{nm}$ light, a large number of valence electrons change from the valence band of the host to the conduction band, becoming excited-state electrons; next, from the conduction band to ${ }^{1} \mathrm{P}_{1}$, and from ${ }^{1} \mathrm{P}_{1} \rightarrow{ }^{3} \mathrm{P}_{1}$ through the ISC process, and then from ${ }^{3} \mathrm{P}_{1} \rightarrow{ }^{1} \mathrm{~S}_{0}$, the energy is released as light by emitting a strong $620-\mathrm{nm}$ visible light; finally, a small portion of the excited-state electrons directly transfer from the valence band back to the conduction band and the energy is released by non-radiative recombination.

The blue light emission at $465 \mathrm{~nm}$ is attributed to the electron transition in the ${ }^{3} \mathrm{P}_{1} \rightarrow{ }^{1} \mathrm{~S}_{0}$ process, and the band deformation occurs because the ${ }^{3} \mathrm{P}$ energy level is affected by the dynamic Jahn-Teller effect [40-44], which causes the three kinds of electron transition in the same ${ }^{3} \mathrm{P}$ energy level to the ground state ${ }^{1} \mathrm{~S}_{0}$. Therefore, when excited by a 340 -nm light wave, the
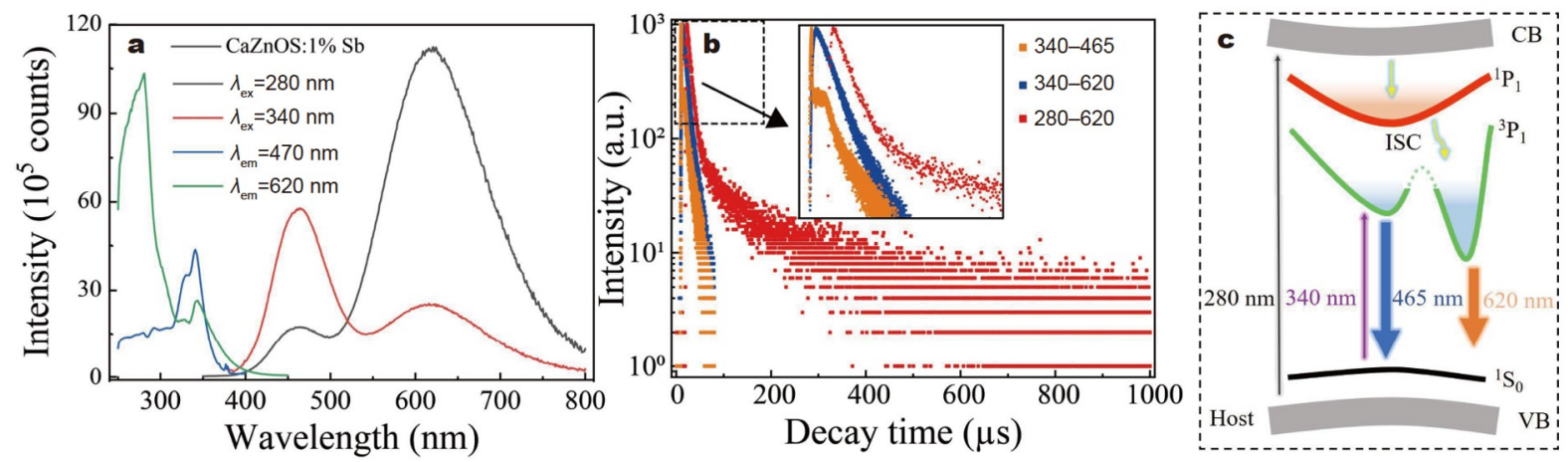

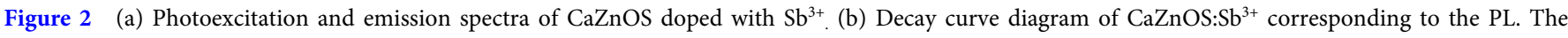
orange curve is the decay of $465 \mathrm{~nm}$ by the $340 \mathrm{~nm}$; the blue curve is the decay of $620 \mathrm{~nm}$ recorded by an excitation wavelength of 340 nm; the red curve corresponds to an excitation wavelength of $280 \mathrm{~nm}$. Inset: the selected delay curves after being enlarged. (c) Schematic diagram of the charge transfer mechanism of $\mathrm{PL}$ process in $\mathrm{Sb}^{3+}$-doped CaZnOS. 
valence electrons transfer from the ground state ${ }^{1} S_{0}$ to the excited state ${ }^{3} \mathrm{P}_{1}$, while most of the excited-state electrons return to the ground state ${ }^{1} \mathrm{~S}_{0}$ to emit a broad emission centred around of $465 \mathrm{~nm}$. Because ${ }^{3} \mathrm{P}_{1} \rightarrow{ }^{1} \mathrm{~S}_{0}$ is a fast decay process [45], there is a fast process in the decay curves of 340-465 and 340-620 nm (Fig. 2b). It can be observed that the ratio of the two main emission peaks ( $465 \mathrm{~nm}: 620 \mathrm{~nm}$ ) is less than 1 (calculated to be approximately 0.60 ) when excited by $307-\mathrm{nm}$ excitation light (Fig. 3a), and the corresponding chromaticity coordinates $(x, y)$ are $(0.4128,0.3340)$. When the excitation wavelength is gradually increased to $331 \mathrm{~nm}$ in steps of $4 \mathrm{~nm}$, the ratio gradually increases and becomes greater than 2 (calculated to be approximately 2.10 ), and the corresponding colour coordinates are $(0.2858,0.2440)$. As the excitation wavelength increases to $355 \mathrm{~nm}$, the ratio gradually decreases and approaches 1 (approximately 1.08), and the corresponding colour coordinates are $(0.3496,0.2932)$. The contrast heights of the two main emission peaks showed good tunability under different excitation wavelengths. We have also documented this dynamic change in Video S1. This is because the ${ }^{3} \mathrm{P}$ energy level of the $\mathrm{Sb}^{3+}$ ion is deformed by the dynamic Jahn-Teller effect. Fig. $3 \mathrm{~b}$ depicts the corresponding colour coordinates for the excitation light of 307-355 nm. By tuning the excitation of a single-doped $\mathrm{CaZnOS}$, the full visible colour range of the emission spectra of $\mathrm{CaZnOS}: \mathrm{Sb}^{3+}$ from orange-red to blue-white can be realised. The novel feature is that a single rare-earth-free phosphor can emit warm white light $(0.3358,0.2803)$ close to standard white light $(0.33,0.33)$. This emission characteristic makes $\mathrm{CaZnOS}: \mathrm{Sb}^{3+} \mathrm{a}$ highly promising material for advanced displays and related piezophotonic fields [2].

In the next section, we discuss the $\mathrm{ML}$ of $\mathrm{CaZnOS}: \mathrm{Sb}^{3+} . \mathrm{ML}$ materials with excellent performance are usually composed of luminescent piezoelectric hosts and luminescent ions. CaZnOS is a new type of ML semiconductor matrix with physical properties similar to $\mathrm{ZnS}$ [46-48], but it has more flexible and optional doping crystal positions. $\mathrm{Mn}^{2+}$ is a well-known dopant in classic mechanoluminescent materials with good performance [48-51]. The ML of $\mathrm{Mn}^{2+}$-doped CaZnOS has been widely reported, which shows a strong orange light emission near $620 \mathrm{~nm}$ and is considered to be the $\mathrm{d}$ - $\mathrm{d}$ transition process between the $\mathrm{Mn}^{2+}$ ion energy levels $\left({ }^{4} \mathrm{~T}_{1}(4 \mathrm{G}) \rightarrow{ }^{6} \mathrm{~A}_{1}(6 \mathrm{~S})\right.$ launch)

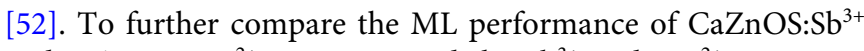
and CaZnOS: $\mathrm{Mn}^{2+}$, we compared the $\mathrm{Sb}^{3+}$ and $\mathrm{Mn}^{2+}$ emissions and normalised the full width at half maximum (FWHM) of their ML in Fig. 4a. It is noteworthy that the FWHM of CaZnOS: $\mathrm{Sb}^{3+}$ is approximately two times larger than that of CaZnOS: $\mathrm{Mn}^{2+}$

In addition, the ML of CaZnOS:Sb ${ }^{3+}$ and $\mathrm{CaZnOS}: \mathrm{Mn}^{2+}$ essentially coincides at $620 \mathrm{~nm}$. The difference is that CaZnOS: $\mathrm{Sb}^{3+}$ has a peak at $465 \mathrm{~nm}$, which is quite consistent with the PL image excited by $280-\mathrm{nm}$ of $\mathrm{CaZnOS}: \mathrm{Sb}^{3+}$, indicating that the $\mathrm{ML}$ of CaZnOS doped with $\mathrm{Sb}^{3+}$ has the same emission process and the same activators. When the CaZnOS:Sb ${ }^{3+}$ crystal is subjected to an external force, the piezoelectric field generated by the coordinated effect of doped ions and defects in the CaZnOS matrix enables electrons to escape from traps to combine with holes in the valence to form an $\mathrm{e}-\mathrm{h}$ pair $[53,54]$. In this process, energy is transferred to $\mathrm{Sb}^{3+}$ ions through non-radiative recombination, which achieves an energy transfer process consistent with PL emission [34-36]. In Fig. 4b, the ML integrated intensity curve corresponding to different $\mathrm{Sb}^{3+}$ ion doping concentrations shows that when the doping concentration is $0.5 \%$, the corresponding ML intensity reaches its maximum value. When the doping concentration exceeded $0.5 \%$, the ML intensity started to decrease. This phenomenon is attributed to the quenching of the luminous intensity caused by the high doping concentration. We also recorded the dynamic ML process of $\mathrm{CaZnOS}: 0.5 \% \mathrm{Sb}^{3+}$ under the scrape of a ball-point pen (Video S2). Fig. 4c shows that the ML peak intensity at $620 \mathrm{~nm}$ increases linearly, while the peak intensity at $465 \mathrm{~nm}$ exhibits a small change under different forces, which makes the ML colour appear orange-red (Fig. S4), and the ML and PL spectra of ZnS: $\mathrm{Sb}^{3+}$ and $\mathrm{CaO}: \mathrm{Sb}^{3+}$ show that the PL and ML only came from CaZnOS:Sb ${ }^{3+}$ (Fig. S5). Therefore, we co-doped $\mathrm{Bi}^{3+}$ and $\mathrm{Sb}^{3+}$ to enhance the peak at $465 \mathrm{~nm}$. Fig. $4 \mathrm{~d}$ shows the ML spectrum of the CaZnOS: $\mathrm{Sb}^{3+} / \mathrm{Bi}^{3+}$ sample, showing an ML emission range of $400-900 \mathrm{~nm}$, which completely contains the visible spectrum $(400-780 \mathrm{~nm})$. We recorded the dynamic ML process (Video S3) of this sample at room temperature and recorded its PL (Fig. S6); it can be seen that $\mathrm{CaZnOS}: \mathrm{Sb}^{3+} / \mathrm{Bi}^{3+}$ appears as warm white ML under the action of the scraping force. The chromaticity coordinates of the ML colours of the three different samples are
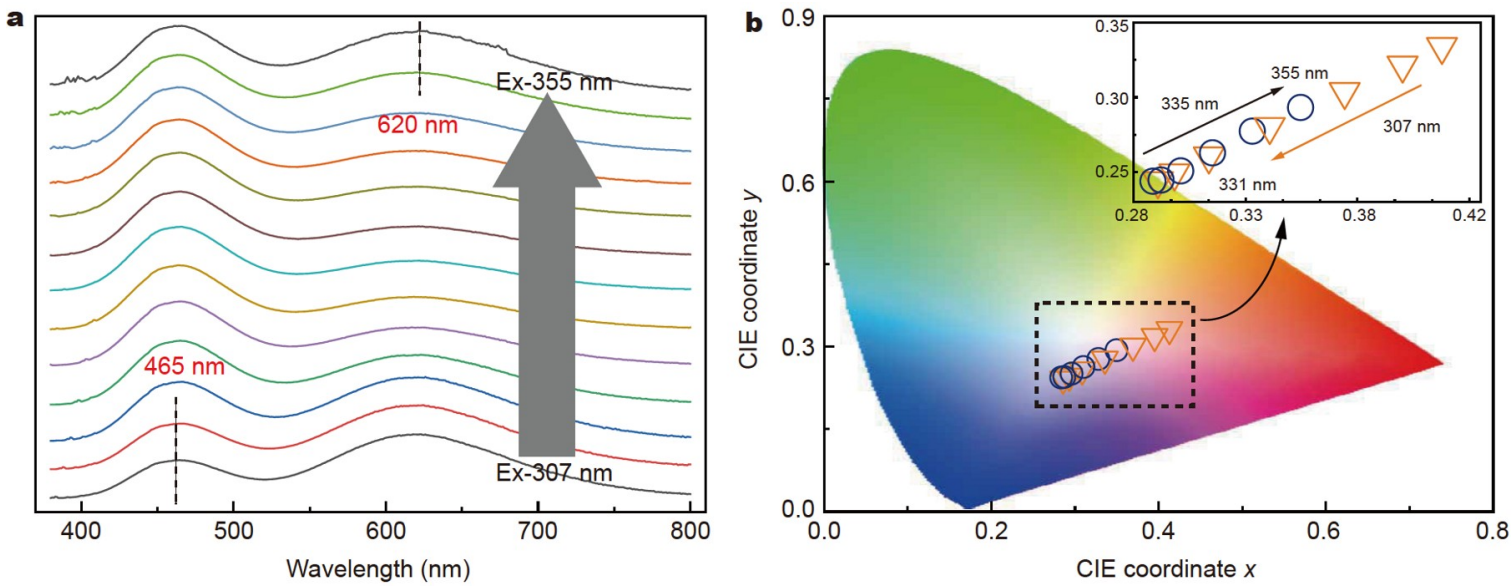

Figure 3 (a) CaZnOS:Sb ${ }^{3+}$ PL emission intensity changes with different excitations from 307 to $355 \mathrm{~nm}$ (adjacent excitation wavelength difference is $4 \mathrm{~nm}$ ). (b) Commission International de l'Eclairage (CIE) shows the colour change of the emitted light wave corresponding to the excitation wavelength of $307-355 \mathrm{~nm}$. Inset: enlarged image of the corresponding chromaticity coordinate point within the dotted line. 

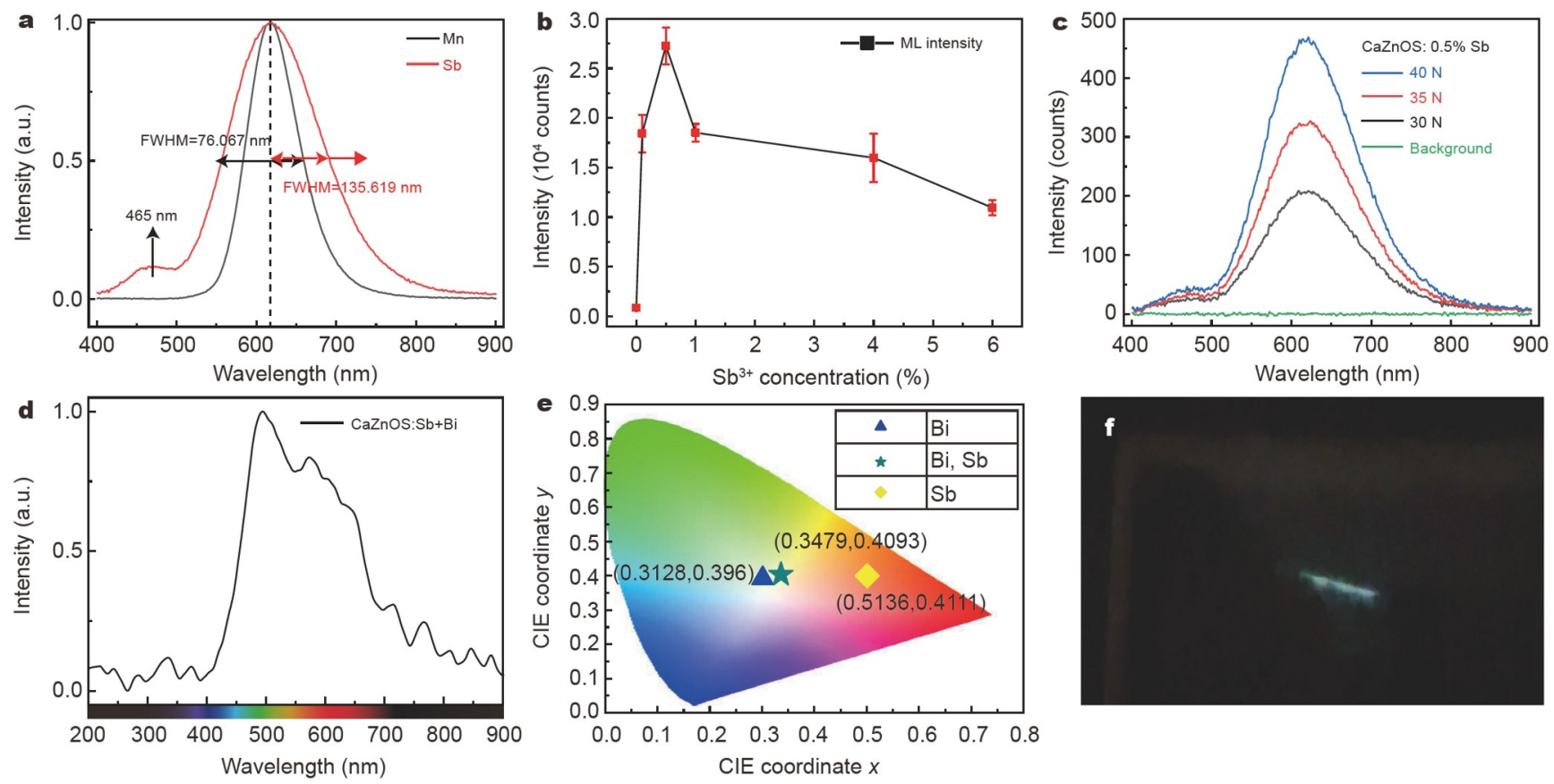

Figure 4 ML studies of CaZnOS:Sb ${ }^{3+}$. (a) Normalised ML spectra of $\mathrm{Sb}^{3+}$ - and $\mathrm{Mn}^{2+}$-doped CaZnOS recorded under the applied force of $60 \mathrm{~N}$, where the FWHMs corresponding to $\mathrm{Sb}^{3+}$ and $\mathrm{Mn}^{2+}$ ions are 135.619 and $76.067 \mathrm{~nm}$, respectively; (b) CaZnOS: $x$ mol\% Sb ${ }^{3+}(x=0,0.1,0.5,1,4$, and 6) ML intensity integral image; (c) ML spectrum of CaZnOS:0.5\% Sb ${ }^{3+}$ at different forces; (d) ML image of CaZnOS co-doped with $4 \% \mathrm{Sb}^{3+}$ and $5 \% \mathrm{Bi}^{3+}$, where the image is smoothed with a window width of 0.05-LOWESS (LOWESS: locally weighted scatterplot smoothing); (e) CIE coordinates of $\mathrm{ML}$ image of $1 \% \mathrm{Bi}^{3+}$-doped CaZnOS, CaZnOS co-doped with $4 \% \mathrm{Sb}^{3+}$ and $5 \% \mathrm{Bi}^{3+}$, and $1 \% \mathrm{Sb}^{3+}$-doped CaZnOS; the coordinates are $(0.3128,0.3960),(0.3479,0.4093)$, and $(0.5136$, 0.4111 ); (f) photograph of ML image at room temperature, corresponding to (d).

shown in Fig. 4e, where we synthesised co-doped CaZnOS: $\mathrm{Sb}^{3+} / \mathrm{Bi}^{3+}$ and $\mathrm{CaZnOS}: \mathrm{Bi}^{3+}$ by the high-temperature solid-phase method [55-57]; these results show that co-doping can effectively change the colour of ML. Fig. $4 \mathrm{f}$ shows a singleframe image taken from the video recording of the dynamic process (Video S3), showing warm white ML emission.

Interestingly, we found that the sample exhibits bright luminescence under X-ray irradiation through the transparent protective window in the process of $\mathrm{X}$-ray powder diffraction, and thus we systematically tested the fluorescence emission of the sample under X-ray excitation [58,59]. The X-ray-induced emission performance of $\mathrm{Sb}^{3+}$-doped $\mathrm{CaZnOS}$ is shown in Fig. 5a, b, and an ultra-wide emission ranging from 300 to $850 \mathrm{~nm}$ was observed in the XIL spectra. When comparing the XIL, PL, and ML spectra, we found that the emission at $465 \mathrm{~nm}$ $<x<500 \mathrm{~nm}$ of XIL was significantly enhanced and the main emission peak shifted forward by $20 \mathrm{~nm}$ compared with PL (with the main emission peak at $620 \mathrm{~nm}$ ), which may be explained by the fact that the X-rays of short wavelength carried higher energy, causing the emission to blue-shift towards shorter wavelengths. When the working current was fixed at $40 \mu \mathrm{A}$, the integrated intensity of the XIL spectra did not increase linearly with the increase in the working voltage. This can be attributed to the increase in the energy carried by the electrons as the accelerating voltage increased, and the X-ray photons generated as the cathode material was bombarded; thus, the number of $\mathrm{e}-\mathrm{h}$ pairs generated by exciting the sample per unit time increased, resulting in a non-linear correlation between the working voltage and the XIL intensity. Furthermore, when we fixed the working voltage at $50 \mathrm{kV}$, the linear change in the XIL intensity was consistent with the change in current. This can be explained by the fact that the XIL intensity linearly increased and the energy of a single X-ray photon remained unchanged with an increase in the working current.

We further tested the XIL of samples with different concentrations, and their integral intensities showed good regularity (Fig. S7). These features make the $\mathrm{CaZnOS}: \mathrm{Sb}^{3+}$ material suitable for X-ray visualisation and sensing applications. Fig. $5 \mathrm{~d}$ shows a real photograph of XIL for the sample with X-ray on (Open) and off (Close, taken $10 \mathrm{~s}$ after the X-ray was turned off), showing a light orange luminescence and a long afterglow phosphorescence characteristic (Video S4). If the particles can be made small enough in the future, they are expected to have applications in biological and chip monitoring [60-65].

\section{CONCLUSION}

We have successfully synthesised a series of $\mathrm{Sb}^{3+}$-doped CaZnOS ML semiconductors, which showed that the single ML material CaZnOS: $\mathrm{Sb}^{3+}$ has broad-spectrum emission and three different emission modes originating from the $\mathrm{Sb}^{3+}$ dopants, i.e., $\mathrm{PL}, \mathrm{ML}$, and XIL. We found that the broad-spectrum emission characteristics of $\mathrm{CaZnOS}: \mathrm{Sb}^{3+}$ are related to the ${ }^{3} \mathrm{P}$ energy level of $\mathrm{Sb}^{3+}$ ions, which is affected by the dynamic Jahn-Teller effect; therefore, its PL emission spectrum has two peaks with tunable intensity at different excitation wavelengths at 465 and $620 \mathrm{~nm}$. By adjusting the excitation wavelength, we can change the PL colour of CaZnOS: $\mathrm{Sb}^{3+}$ from orange to blue. This feature of adjustable bimodal intensity was first discovered in all single ML materials, and thus it is expected to be used in the field of rareearth-free and low-toxicity white light displays, as well as in mechanical information coding and transmission. CaZnOS: $\mathrm{Sb}^{3+}$ shows a broad ML emission, including a two-peak emission (465 

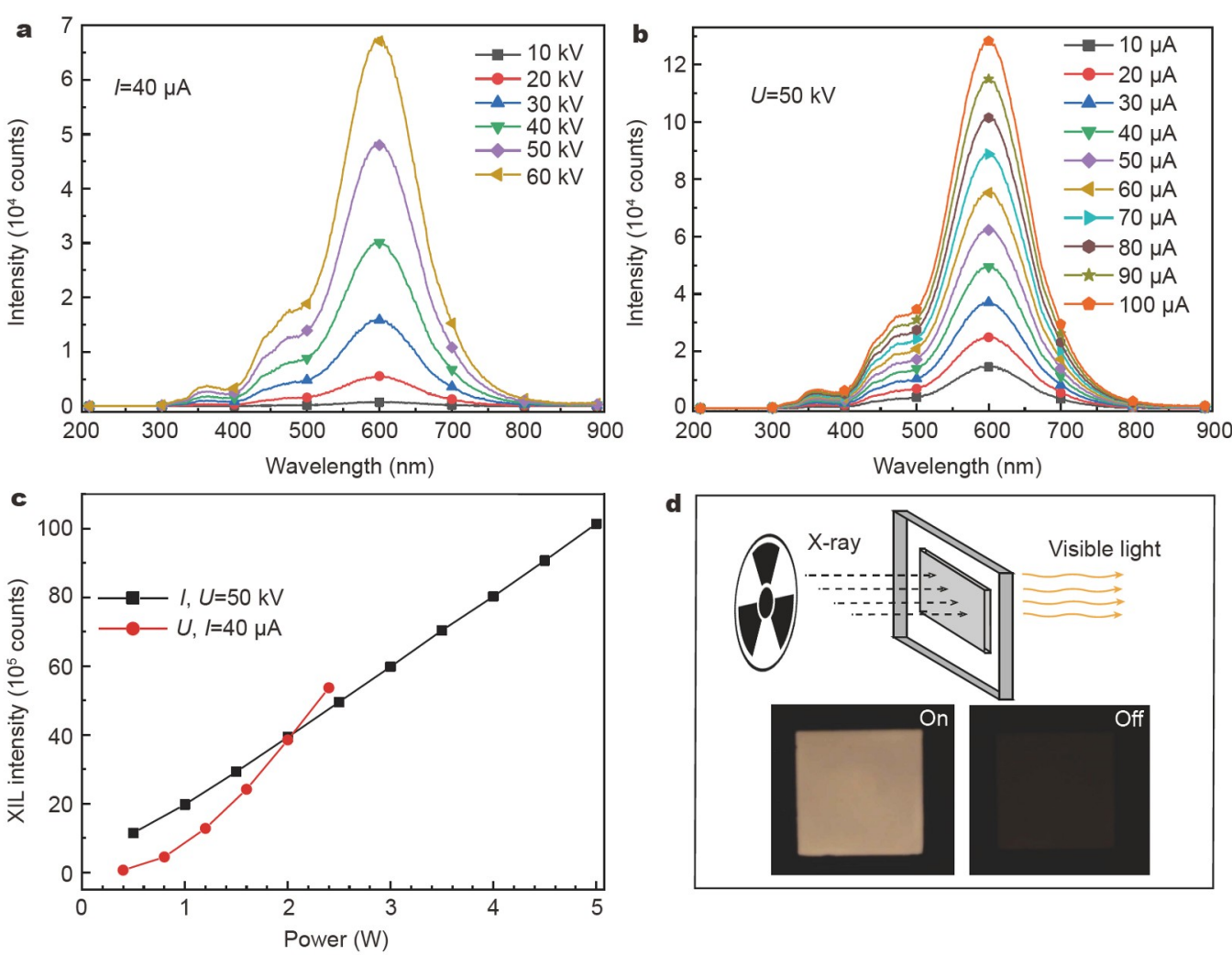

Figure 5 XIL spectra of CaZnOS:Sb ${ }^{3+}$ : (a) $I=40 \mu \mathrm{A}, U=10-60 \mathrm{kV}$ and (b) $U=50 \mathrm{kV}, I=10-100 \mu \mathrm{A}$. (c) Relationship between the integrated intensity calculated by the XIL in (a) and (b) and the X-ray tube power $(P=U I)$. (d) Schematic diagram for the XIL (upper) and (lower) XIL photographs of the sample with X-ray on (Open) and off (Close, taken $10 \mathrm{~s}$ after the X-ray was turned off).

and $620 \mathrm{~nm}$ ), which is consistent with the PL, and we also found that the ML colour will change because of the change in the two peak intensities under different forces. In addition, the FWHM of the ML of CaZnOS:Sb ${ }^{3+}$ is approximately 1.78 times wider than that of the classical ML material CaZnOS: $\mathrm{Mn}^{2+}$. Co-doping with $\mathrm{Bi}^{3+}$ can achieve warm white broadband ML emission from

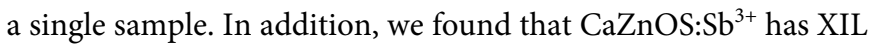
and long afterglow characteristics, which provides the possibility for the application of $\mathrm{CaZnOS}: \mathrm{Sb}^{3+}$ in X-ray intensity visualisation. The CaZnOS:Sb ${ }^{3+}$ layered semiconductor is expected to be applied in the fields of stress sensors, UV light and X-ray detection, white light illumination, and laser wavelength visualisation.

Received 17 September 2021; accepted 25 October 2021; published online 30 November 2021

1 Peng D, Chen B, Wang F. Recent advances in doped mechanoluminescent phosphors. ChemPlusChem, 2015, 80: 1209-1215

2 Wang X, Peng D, Huang B, et al. Piezophotonic effect based on mechanoluminescent materials for advanced flexible optoelectronic applications. Nano Energy, 2019, 55: 389-400

3 Wang C, Peng D, Pan C. Mechanoluminescence materials for advanced artificial skin. Sci Bull, 2020, 65: 1147-1149

4 Peng D, Wang C, Ma R, et al. Mechanoluminescent materials for athletic analytics in sports science. Sci Bull, 2020, 66: 206-209

5 Kim Y, Kim JS, Kim GW. A novel frequency selectivity approach based on travelling wave propagation in mechanoluminescence basilar membrane for artificial cochlea. Sci Rep, 2018, 8: 12023

6 Zhuang Y, Xie RJ. Mechanoluminescence rebrightening the prospects of stress sensing: A review. Adv Mater, 2021, : 2005925
7 Xu CN, Watanabe T, Akiyama M, et al. Direct view of stress distribution in solid by mechanoluminescence. Appl Phys Lett, 1999, 74: 2414-2416

8 Xie Y, Tu J, Zhang T, et al. Mechanoluminescence from pure hydrocarbon AIEgen. Chem Commun, 2017, 53: 11330-11333

9 Zhang JC, Pan C, Zhu YF, et al. Achieving thermo-mechano-optoresponsive bitemporal colorful luminescence via multiplexing of dual lanthanides in piezoelectric particles and its multidimensional anticounterfeiting. Adv Mater, 2018, 30: 1804644

$10 \mathrm{Tu}$ D, Xu CN, Kamimura S, et al. Ferroelectric $\mathrm{Sr}_{3} \mathrm{Sn}_{2} \mathrm{O}_{7}: \mathrm{Nd}^{3+}$ : A new multipiezo material with ultrasensitive and sustainable near-infrared piezoluminescence. Adv Mater, 2020, 32: 1908083

11 Joos JJ, Lejaeghere K, Korthout $\mathrm{K}$, et al. Charge transfer induced energy storage in CaZnOS:Mn-Insight from experimental and computational spectroscopy. Phys Chem Chem Phys, 2017, 19: 9075-9085

12 Zhang JC, Xu CN, Kamimura S, et al. An intense elastico-mechanoluminescence material CaZnOS: $\mathrm{Mn}^{2+}$ for sensing and imaging multiple mechanical stresses. Opt Express, 2013, 21: 12976-12986

$13 \mathrm{Tu} \mathrm{D}, \mathrm{Xu}$ CN, Fujio Y, et al. Mechanism of mechanical quenching and mechanoluminescence in phosphorescent CaZnOS:Cu. Light Sci Appl, 2015, 4: e356

14 Tu D, Peng D, Xu CN, et al. Mechanoluminescence properties of redemitting piezoelectric semiconductor MZnOS: $\mathrm{Mn}^{2+}(\mathrm{M}=\mathrm{Ca}, \mathrm{Ba})$ with layered structure. J Ceram Soc Jpn, 2016, 124: 702-705

15 Yuan J, Yang Y, Yang X, et al. Regulating the trap distribution to achieve high-contrast mechanoluminescence with an extended saturation threshold through co-doping $\mathrm{Nd}^{3+}$ into $\mathrm{CaZnOS}: \mathrm{Bi}^{3+}, \mathrm{Li}^{+}$. J Mater Chem C, 2021, 9: 7689-7696

16 Li L, Wondraczek L, Li L, et al. CaZnOS: $\mathrm{Nd}^{3+}$ emits tissue-penetrating near-infrared light upon force loading. ACS Appl Mater Interfaces, 2018, 10: 14509-14516

17 Li L, Wong KL, Li P, et al. Mechanoluminescence properties of $\mathrm{Mn}^{2+}$ doped BaZnOS phosphor. J Mater Chem C, 2016, 4: 8166-8170 
18 Wang W, Peng D, Zhang H, et al. Mechanically induced strong red emission in samarium ions doped piezoelectric semiconductor $\mathrm{CaZnOS}$ for dynamic pressure sensing and imaging. Optics Commun, 2017, 395: 24-28

19 Peng D, Jiang Y, Huang B, et al. A ZnS/CaZnOS heterojunction for efficient mechanical-to-optical energy conversion by conduction band offset. Adv Mater, 2020, 32: 1907747

20 Du Y, Jiang Y, Sun T, et al. Mechanically excited multicolor luminescence in lanthanide ions. Adv Mater, 2019, 31: 1807062

21 Chen W, Zhuang Y, Chen C, et al. Lanthanide-doped metal-organic frameworks with multicolor mechanoluminescence. Sci China Mater, 2021, 64: 931-941

22 Jeong SM, Song S, Joo KI, et al. Bright, wind-driven white mechanoluminescence from zinc sulphide microparticles embedded in a polydimethylsiloxane elastomer. Energy Environ Sci, 2014, 7: 33383346

23 Zhao XJ, Kuang SY, Wang ZL, et al. Electricity-free electroluminescence excited by droplet impact driven triboelectric field on solid-liquid interface. Nano Energy, 2020, 75: 104823

$24 \mathrm{Tu} \mathrm{D}, \mathrm{Xu} \mathrm{CN}$, Yoshida A, et al. $\mathrm{LiNbO}_{3}: \mathrm{Pr}^{3+}$ : A multipiezo material with simultaneous piezoelectricity and sensitive piezoluminescence. Adv Mater, 2017, 29: 1606914

25 Zhuang Y, Tu D, Chen C, et al. Force-induced charge carrier storage: A new route for stress recording. Light Sci Appl, 2020, 9: 182

26 Chen C, Zhuang Y, Tu D, et al. Creating visible-to-near-infrared mechanoluminescence in mixed-anion compounds $\mathrm{SrZn}_{2} \mathrm{~S}_{2} \mathrm{O}$ and $\mathrm{SrZnSO}$. Nano Energy, 2019, 68: 104329

27 Chen C, Zhuang Y, Li X, et al. Achieving remote stress and temperature dual-modal imaging by double-lanthanide-activated mechanoluminescent materials. Adv Funct Mater, 2021, 31: 2101567

28 Zhao Y, Peng D, Bai G, et al. Piezophotonics: Multiresponsive emissions in luminescent ions doped quaternary piezophotonic materials for mechanical-to-optical energy conversion and sensing applications. Adv Funct Mater, 2021, 31: 2170160

29 Su M, Li P, Zheng S, et al. Largely enhanced elastico-mechanoluminescence of CaZnOS: $\mathrm{Mn}^{2+}$ by co-doping with $\mathrm{Nd}^{3+}$ ions. J Lumin, 2020, 217: 116777

30 Jing Y, Liu Y, Li M, et al. Photoluminescence of singlet/triplet selftrapped excitons in $\mathrm{Sb}^{3+}$-based metal halides. Adv Opt Mater, 2021, 9: 2002213

31 Li S, Luo J, Liu J, et al. Self-trapped excitons in all-inorganic halide perovskites: Fundamentals, status, and potential applications. J Phys Chem Lett, 2019, 10: 1999-2007

32 Morad V, Shynkarenko Y, Yakunin S, et al. Disphenoidal zero-dimensional lead, tin, and germanium halides: Highly emissive singlet and triplet self-trapped excitons and X-ray scintillation. J Am Chem Soc, 2019, 141: 9764-9768

33 Zhang $\mathrm{C}$, Zhang $\mathrm{M}$, Zheng $\mathrm{W}$, et al. A new class of luminescent nanoprobes based on main-group $\mathrm{Sb}^{3+}$ emitters. Nano Res, 2022, 15: 179185

34 Jing $\mathrm{Y}$, Liu $\mathrm{Y}$, Zhao J, et al. $\mathrm{Sb}^{3+}$ doping-induced triplet self-trapped excitons emission in lead-free $\mathrm{Cs}_{2} \mathrm{SnCl}_{6}$ nanocrystals. J Phys Chem Lett, 2019, 10: 7439-7444

35 Zhou C, Lin H, Tian Y, et al. Luminescent zero-dimensional organic metal halide hybrids with near-unity quantum efficiency. Chem Sci, 2018, 9: 586-593

36 Pal J, Manna S, Mondal A, et al. Colloidal synthesis and photophysics of $\mathrm{M}_{3} \mathrm{Sb}_{2} \mathrm{I}_{9}(\mathrm{M}=\mathrm{Cs}$ and $\mathrm{Rb})$ nanocrystals: Lead-free perovskites. Angew Chem, 2017, 129: 14375-14379

37 Ranfagni A, Mugnai D, Bacci M, et al. The optical properties of thallium-like impurities in alkali-halide crystals. Adv Phys, 1983, 32: 823905

38 Jacobs PWM. Alkali halide crystals containing impurity ions with the $n \mathrm{~s}^{2}$ ground-state electronic configuration. J Phys Chem Solids, 1991, 52: $35-67$

39 Noculak A, Morad V, McCall KM, et al. Bright blue and green luminescence of $\mathrm{Sb}(\mathrm{III})$ in double perovskite $\mathrm{Cs}_{2} \mathrm{MInCl}_{6}(\mathrm{M}=\mathrm{Na}, \mathrm{K})$ matrices. Chem Mater, 2020, 32: 5118-5124

40 Oomen EWJL, Smit WMA, Blasse G. Jahn-Teller effect in the $\mathrm{Sb}^{3+}$ emission in zircon-structured phosphates. Chem Phys Lett, 1984, 112: 547-550

41 Chen B, Guo Y, Wang Y, et al. Multiexcitonic emission in zero-dimensional $\mathrm{Cs}_{2} \mathrm{ZrCl}_{6}: \mathrm{Sb}^{3+}$ perovskite crystals. J Am Chem Soc, 2021, 143 : 17599-17606

42 Oomen EWJL, Smit WMA, Blasse G. Jahn-Teller effect in the emission and excitation spectra of the $\mathrm{Sb}^{3+}$ ion in $\mathrm{LPO}_{4}(\mathrm{~L}=\mathrm{Sc}, \mathrm{Lu}, \mathrm{Y})$. Phys Rev B, 1988, 37: 18-26

43 Oomen EWJL, Smit WMA, Blasse G. On the luminescence of $\mathrm{Sb}^{3+}$ in $\mathrm{Cs}_{2} \mathrm{NaMCl}_{6}$ (with $\mathrm{M}=\mathrm{Sc}, \mathrm{Y}, \mathrm{La}$ ): A model system for the study of trivalent $s^{2}$ ions. J Phys C-Solid State Phys, 1986, 19: 3263-3272

44 Cheng X, Li R, Zheng W, et al. Tailoring the broadband emission in allinorganic lead-free 0D in-based halides through $\mathrm{Sb}^{3+}$ doping. Adv Opt Mater, 2021, 9: 2100434

45 Donker H, Yamashita N, Smit WMA, et al. Luminescence decay times of the $\mathrm{Sb}^{3+}, \mathrm{Pb}^{2+}$, and $\mathrm{Bi}^{3+}$ ions in alkaline-earth sulfides. Phys Stat $\mathrm{Sol} \mathrm{B}$, 1989, 156: 537-544

46 Wang F, Wang F, Wang X, et al. Mechanoluminescence enhancement of $\mathrm{ZnS}: \mathrm{Cu}, \mathrm{Mn}$ with piezotronic effect induced trap-depth reduction originated from PVDF ferroelectric film. Nano Energy, 2019, 63: 103861

47 Li H, Zhang Y, Dai H, et al. A self-powered porous ZnS/PVDF-HFP mechanoluminescent composite film that converts human movement into eye-readable light. Nanoscale, 2018, 10: 5489-5495

48 Gan J, Kang MG, Meeker MA, et al. Enhanced piezoluminescence in non-stoichiometric $\mathrm{ZnS}: \mathrm{Cu}$ microparticle based light emitting elastomers. J Mater Chem C, 2017, 5: 5387-5394

49 Duan CJ, Delsing ACA, Hintzen HT. Photoluminescence properties of novel red-emitting $\mathrm{Mn}^{2+}$-activated $\mathrm{MZnOS}(\mathrm{M}=\mathrm{Ca}, \mathrm{Ba})$ phosphors. Chem Mater, 2009, 21: 1010-1016

$50 \mathrm{Xu} \mathrm{Z,} \mathrm{Xia} \mathrm{Z,} \mathrm{Lei} \mathrm{B,} \mathrm{et} \mathrm{al.} \mathrm{Full} \mathrm{color} \mathrm{control} \mathrm{and} \mathrm{white} \mathrm{emission} \mathrm{from}$ CaZnOS: $\mathrm{Ce}^{3+}, \mathrm{Na}^{+}, \mathrm{Mn}^{2+}$ phosphors via energy transfer. J Mater Chem C, 2016, 4: 9711-9716

51 Zhang X, Zhao J, Chen B, et al. Tuning multimode luminescence in lanthanide(III) and manganese(II) co-doped CaZnOS crystals. Adv Opt Mater, 2020, 8: 2000274

52 Zhang JC, Zhao LZ, Long YZ, et al. Color manipulation of intense multiluminescence from CaZnOS: $\mathrm{Mn}^{2+}$ by $\mathrm{Mn}^{2+}$ concentration effect. Chem Mater, 2015, 27: 7481-7489

53 Zhang JC, Wang X, Marriott G, et al. Trap-controlled mechanoluminescent materials. Prog Mater Sci, 2019, 103: 678-742

54 Ricci PC, Satta J, Chiriu D, et al. Optical and vibrational properties of CaZnOS: The role of intrinsic defects. J Alloys Compd, 2018, 777: 225233

55 Pan DJ, Yang YL, Yang XC, et al. The effect of site occupation and valence state of $\mathrm{Bi}$ on the luminescence properties of Bi-activated oxysulfide MZnOS $(\mathrm{M}=\mathrm{Ca}, \mathrm{Ba})$ with layer structure. J Alloys Compd, 2018, 742: 1037-1045

56 Yang YL, Li QL, Yang XC, et al. Color manipulation of $\mathrm{Bi}^{3+}$-activated CaZnOS under stress with ultra-high efficiency and low threshold for anticounterfeiting applications. J Mater Chem C, 2020, 8: 3308-3315

57 Yang YL, Yuan JY, Fan YT, et al. Efficient energy transfer from $\mathrm{Bi}^{3+}$ to $\mathrm{Mn}^{2+}$ in CaZnOS for WLED application. Dalton Trans, 2021, 50: $11130-11136$

58 Xie L, Hong Z, Zan J, et al. Broadband detection of X-ray, ultraviolet and near-infrared photons using solution-processed perovskite-lanthanide nanotransducers. Adv Mater, 2021, 33: 2101852

59 Zeng Z, Huang B, Wang X, et al. Multimodal luminescent $\mathrm{Yb}^{3+} / \mathrm{Er}^{3+} /$ $\mathrm{Bi}^{3+}$-doped perovskite single crystals for $\mathrm{X}$-ray detection and anticounterfeiting. Adv Mater, 2020, 32: 2004506

60 Chen Q, Wu J, Ou X, et al. All-inorganic perovskite nanocrystal scintillators. Nature, 2018, 561: 88-93

61 Ou X, Qin X, Huang B, et al. High-resolution X-ray luminescence extension imaging. Nature, 2021, 590: 410-415

62 Zhuang Y, Chen D, Chen W, et al. X-ray-charged bright persistent luminescence in $\mathrm{NaYF}_{4}: \mathrm{Ln}^{3+} @ \mathrm{NaYF}_{4}$ nanoparticles for multidimensional optical information storage. Light Sci Appl, 2021, 10: 132

63 Matsubara T, Yanagida T, Kawaguchi N, et al. Remote control of neura function by X-ray-induced scintillation. Nat Commun, 2021, 12: 4478 
64 Pei P, Chen Y, Sun C, et al. X-ray-activated persistent luminescence nanomaterials for NIR-II imaging. Nat Nanotechnol, 2021, 16: 10111018

65 Li X, Chen J, Yang D, et al. $\mathrm{Mn}^{2+}$ induced significant improvement and robust stability of radioluminescence in $\mathrm{Cs}_{3} \mathrm{Cu}_{2} \mathrm{I}_{5}$ for high-performance nuclear battery. Nat Commun, 2021, 12: 3879

Acknowledgements This work was supported by the National Natural Science Foundation of China (61875136 and 52002246), the Fundamental Research Project of Guangdong Province (2020A1515011315), Shenzhen Fundamental Research Project (JCYJ20190808170601664), the Science and Technology Innovation Project of Shenzhen Excellent Talents (RCBS20200714114919006), and the Scientific Research Foundation as Phase II construction of high-level University for the Youth Scholars of Shenzhen University 2019 (000002110223).

Author contributions Li X designed the experiments, tested the characterizations and wrote the original draft. Zheng Y tested the characterizations, and revised the original draft. Ma $\mathrm{R}$ designed the experiments, and revised the original draft. Huang $\mathrm{Z}$, Wang $\mathrm{C}$, and Zhu $\mathrm{M}$ helped in the data collections. Jiang $\mathrm{F}$ helped in the X-ray diffraction data collections and analysed the data. Du Y, Chen X, Huang B, and Wang F helped with the resources and supervision. Wang B and Wang Y helped in the photography. Peng D guided the whole project and revised the manuscript.

Conflict of interest The authors declare that they have no conflict of interest.

Supplementary information Supporting data are available in the online version of the paper.

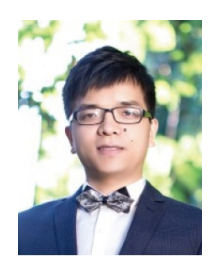

Dengfeng Peng received his BS degree (2006) in physics from Xinjiang University and $\mathrm{PhD}$ degree (2013) in materials science and engineering from Tongji University. He spent one year as a joint $\mathrm{PhD}$ student at the National Institute of Advanced Industrial Science and Technology (AIST) in Japan. He carried out postdoctoral research at City University of Hong Kong (2013), Beijing Institute of Nanoenergy and Nanosystems, Chinese Academy of Sciences (2015), and The Hong Kong Polytechnic University (2016). His research interests include the synthesis and mechanistic investigation of functional materials for applications in optoelectronics, flexible electronics and advanced energy devices.

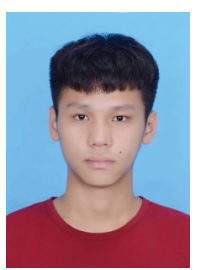

Xu Li received his BS degree (2020) from the College of Physics and Optoelectronic Engineering, Shenzhen University. His research interests include the synthesis and mechanistic investigation of functional materials for applications in optoelectronics, flexible electronics and advanced energy devices. He is now studying at Shenzhen University for his master degree, focusing on mechanoluminescence materials.

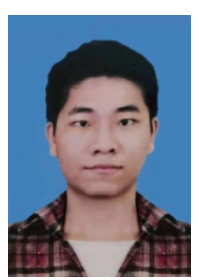

Yuantian Zheng received his BS degree (2020) from the College of Physics and Optoelectronic Engineering, Shenzhen University. His research interests include the synthesis and research of new luminescent materials, such as mechanoluminescent and photoluminescent materials. He is now studying at Shenzhen University for his master degree, focusing on mechanoluminescence materials.

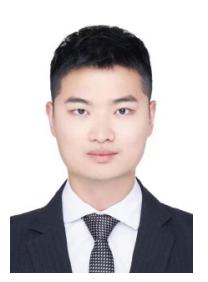

Ronghua Ma received his BS degree (2012) and $\mathrm{PhD}$ degree (2017) in materials science and engineering, Zhejiang University. He worked at Semiconductor Manufacturing International Corporation (SMIC) for one year as a thinfilm process developing engineer. He carried out postdoctoral research at Shenzhen University (2019). His research interests include luminescent glass and glass ceramics, and ML materials. He is now working at Chen Du Guan Ming Glass Co., ltd., focusing on the R\&D of optical glass.

\section{$S b$ 掺杂的CaZnOS层状半导体中的宽带多模发射}

李旭 ${ }^{1 \dagger}$, 郑元钿 ${ }^{1 \dagger}$, 马荣华 ${ }^{1 \dagger}$, 黄泽锋 ${ }^{1}$, 王春枫 ${ }^{1}$, 朱明炬 ${ }^{1}$, 蒋福春 ${ }^{1}$, 杜阳阳 ${ }^{2}$, 陈献 ${ }^{2}$, 黄勃龙 ${ }^{3}$, 王锋 ${ }^{4}$, 王博涵 ${ }^{5}$, 王瑀 ${ }^{5}$, 彭登峰 $1^{*}$

摘要 力致发光 $(\mathrm{ML})$ 智能材料由于其独特的机械能-光能转换特性, 有望用于应力传感器、新型显示和先进的柔性光电器件. 然而, 单一材 料的窄波长范围ML发射特性限制了它们的应用范围. 在这项工作中, 我们报道了 $\mathrm{Sb}$ 掺杂的CaZnOS层状半导体中的宽带多模态发射. 使用高 温固相法合成了一系列具有不同 $\mathrm{Sb}^{3+}$ 掺杂浓度的CaZnOS层状结构粉 末. CaZnOS:Sb ${ }^{3+}$ 荧光粉实现了 400-900 nm ML的宽谱发光范围, 可调 光致发光, 两个发射峰位于 465 和 $620 \mathrm{~nm}$, 我们还系统研究了X射线诱导 发光特性. 我们还实现了 $\mathrm{Sb}^{3+}$ 和 $\mathrm{Bi}^{3+}$ 共掺杂样品的超宽暖白光ML发射. 因此, 这些 ML 苂光粉将有望用于智能照明、显示、可见应力传感器 以及 $\mathrm{X}$ 射线成像和检测. 